\title{
Aspectos da sexualidade na adolescência
}

\section{Aspects of sexuality in adolescence}

\author{
JoséRoberto da Silva Brêtas ${ }^{1}$ \\ Concei ção Vieira da Silva Ohara ${ }^{2}$ \\ Dulcilene Pereira Jardim ${ }^{3}$ \\ Wagner deAguiar Junior ${ }^{4}$ \\ JoséRodrigo deOliveira ${ }^{2}$
}

\footnotetext{
${ }^{1}$ Grupo de Estudos sobre Corporalidadee Promoção da Saúde (GECOPROS), UniversidadeFederal deSão Paulo. Rua Napoleão de Barros 754. 04024-001 São Paulo SP. bretas@ymail.com ${ }^{2}$ U niversidade Federal de São Paulo.

${ }^{3}$ Universidade de Santo Amaro.

${ }^{4}$ Curso de Graduação em Enfermagem, Universidade Federal deSão Paulo.
}

\begin{abstract}
The study involved 920 adolescents between 12 and 19 years of age in junior and senior high schools of the region of Santo Eduardo of the city of Embu, São Paulo. The objective was to identify aspects of sexuality of adolescents of both sexes. Data were collected through a structured questionnaire, the results of which established the difference between boys and gi rls with respect to their quest for specific information about sexuality; $39 \%$ of boys and $17 \%$ of girls practiced sexual intercourse, and among these, $77 \%$ of boys and $84 \%$ of girls used preservativos.
\end{abstract}

Key words Adolescente, Adolescent Development, Sexual behavior, Sexuality
Resumo 0 estudo envolveu 920 adolescentes entre 12 e 19 anos de idade em escolas de ensino fundamental emédio da região deSanto Eduardo do município de Embu, São Paulo. Teve por objetivo identificar aspectos da sexualidadedeadolescentes de ambos os sexos. Os dados foram obtidos por meio de um questionário estruturado, cujos resultados demonstraram a equivalência entregarotas e rapazes com relação à busca de informações específicas sobre sexualidade; $39 \%$ dos rapazes e $17 \%$ das garotas tinham prática sexual, destes, $77 \%$ dos rapazes e $84 \%$ das garotas utilizavam preservativo.

Palavras-chave Adolescência, Comportamento sexual, Desenvolvimento do Adolescente, Sexualidade 


\section{Introdução}

A adolescência é um período muito especial no desenvolvimento humano, considerada a transição entrea infância ea idadeadulta, caracterizada por intenso crescimento e desenvolvimento que se manifesta por marcantes transformações anatômicas, fisiológicas, psicológicas e sociais. Em um contexto mais psicológico, éa etapa na qual o indivíduo busca a identidadeadulta, apoiando-se nas primeiras relações afetivas, já interiorizadas, que teve com seus familiares everificando a realidade que a sua sociedade Ihe oferece ${ }^{1}$.

Com o decorrer do amadurecimento do processo deadolescer, diante do novo corpo queestá surgindo, os adolescentes passam a preocuparse e valorizá-lo, principalmente na aparência visual, adotando comportamentos sociais e sexuais atribuídos a cada sexo².

Estes elementos constitutivos configuram a identidade do adolescente, em que éimportante considerar os processos sociais e culturais que de certa forma delineiam a construção desta identidade. A identidade constitui-setalvez, o fator central do gênero e da sexualidade, tendo em vista a identificação desta enquanto processo constante de mudança, como também nas suas implicações para a experiência da vida sexual.

A sexualidade é algo que se constroi e aprende, sendo parte integrante do desenvolvimento da personalidade, capaz de interferir no processo de aprendizagem, na saúde mental e física do indivíduo ${ }^{3}$. Assim, entendemos quetoda essa transformação biológica e psicológica também acarreta em mudanças na convivência social. 0 adolescente começa a se relacionar com o "grupo", inicialmente separados, meninas em um grupo e meninas em outro, no exercício da bissexualidade ${ }^{4}$, posteriormente, pouco a pouco, exercitam possibilidades de relacionamento com os outros.

Diante deste contexto, ressaltamos a importância do presente estudo para obtenção de conhecimento sobre al guns aspectos da sexualidade da população de adolescentes e na formação de um banco de dados destinado a alimentar o conteúdo das ações educativas nas escolas junto à população estudada.

Este estudo faz parte de um conjunto de pesquisas-intervenção que estão sendo desenvolvidas junto a adolescentes e jovens que frequentam algumas escolas de ensino fundamental e médio da região de Santo Eduardo no município de Embu, São Paulo. Visou coletar informações para subsidiar a elaboração de ações voltadas à promoção da saúde, por meio da prática da ori- entação sexual materializada pelo Projeto de Extensão Universitária "Corporalidade e Promoção da Saúde" da Universidade Federal de São Paulo (UNIFESP).

N estecontexto, esteestudo teve como objetivo identificar e comparar alguns aspectos do comportamento sexual de adolescentes do sexo masculino efeminino.

\section{M etodologia}

Trata-se de um estudo exploratório com abordagem quantitativa. Este tipo de estudo, tem por finalidadedesenvolver, esclarecer emodificar conceitos e ideias, tendo em vista, a formulação de problemas mais precisos para estudos posteriores $^{5}$. 0 mesmo foi desenvolvido com o objetivo de proporcionar visão geral, de tipo aproximativo, acerca da sexualidade deum grupo específico de adolescentes. Esta abordagem permitiu que 0 pesquisador conhecesse e interpretasse a realidadesem nela interferir. Interessa-se em descobrir e observar fenômenos, procurando descrevêlos e interpretá-los. Desta maneira deseja-se conhecer a natureza do fenômeno, sua composição, processos que o constituem ou nele se real izam ${ }^{5,6}$.

Vale ressaltar que o projeto deste estudo foi aprovado pelo Comitê de Ética da UNIFESP e obedeceu aos padrões estabelecidos pela Resolução 196/96, que trata das Normas de Pesquisa Envolvendo Seres Humanos?.

0 recorte etário da população estudada segue a definição da O rganização M undial da Saúde para Adolescência ${ }^{8}$, representada por indivíduos na faixa etária entre 10 e 19 anos.

A população deste estudo foi constituída em sua totalidade por 920 adolescentes (444 / 48\% do sexo masculino e 476 / 52\% feminino), com idade entre 12 e 19 anos, que frequentavam três escolas estaduais de ensino fundamental emédio na Região de Santo Eduardo, do município de Embu. Como princípio de inclusão adotou-se: estar matriculado em uma das três escolas e participando das atividades educativas do Projeto de Extensão Universitária “Corporalidade e Promoção da Saúde".

A população estudada mostrou que $74 \%$ do sexo masculino / $67 \%$ feminino encontravam-se cursando o ensino fundamental, enquanto $26 \%$ masculino / 33\% feminino o ensino médio. Quanto à religião, a maioria referiu ser católica ( $50 \%$ masculino / 64\% feminino), seguido dos evangélicos (18\% masculino / 13\% feminino), espíritas ( $1 \%$ masculino / feminino), testemunha de Jeo- 
vá ( $2 \%$ masculino / $1 \%$ feminino) e os agnósti$\cos$ ( $29 \%$ masculino / $21 \%$ feminino). Com relação ao estado civil 100\% masculino / $89 \%$ feminino eram solteiros e apenas $1 \%$ feminino se declarou casado.

A coleta de dados deu-se entre 2004 e 2005, mediante a aplicação de um questionário semiestruturado, de múltipla escolha, auto-aplicado em sala de aula e de forma anônima, contendo 23 questões representando as variáveis relacionadas aos dados sócio-demográficos (idade, sexo, escolaridade, religião, estado civil) para caracterização da população estudada e do comportamento sexual (conhecimento sobre sexualidade, masturbação, namoro, orientação sexual, virgindade, relacionamento sexual, contracepção, aborto).

Os dados obtidos foram analisados e interpretados em um contexto quantitativo, expressos mediante símbolos numéricos.

\section{Resultados}

Os resultados relacionados ao comportamento sexual dos adolescentes estudados foram analisados, organizados e apresentados a seguir:

Descobriu-se que $67 \%$ dos adolescentes do sexo masculino e $71 \%$ feminino buscavam informações sobre sexualidade. Quanto ao conhecimento sobre sexo e sexualidade, $49 \%$ masculino / 51\% feminino consideraram suficienteseu grau de conhecimento sobre o assunto, enquanto que $43 \%$ masculino / $41 \%$ feminino consideravam insuficiente. Como fonte de informação sobre sexualidade, $31 \%$ masculino / $36 \%$ feminino procuravam os pais, $24 \%$ masculino / $31 \%$ feminino os amigos, $1 \%$ feminino buscavam profissionais da área da saúde, $2 \%$ feminino informações em livros, $9 \%$ masculino / $7 \%$ feminino os professorese $22 \%$ masculino / 13\% feminino não conversavam com ninguém sobre 0 assunto.

Quanto ao ato da masturbação, observouseque $53 \%$ masculino / $12 \%$ feminino o praticavam. D os adolescentes que se masturbavam, 37\% masculino / $43 \%$ feminino praticavam uma vez por semana, $46 \%$ masculino / $27 \%$ feminino duas a três vezes por semana, 12\% masculino / 3\% feminino quatro a cinco vezes por semana, e $5 \%$ masculino / 17\% feminino mais que cinco vezes por semana.

Com referência ao namoro, 59\% masculino / $60 \%$ feminino referiram não existir idade para iniciar um namoro. Ainda com relação ao namoro, 50\% masculino acharam que a idade para iniciar o namoro era entre 13 e 15 anos, enquanto $70 \%$ feminino entre 14 e 16 anos. Os dados obtidos indicaram que $70 \%$ masculino / $63 \%$ feminino já haviam namorado ou namoravam na ocasião do estudo, porém 30\% masculino / 37\% feminino ainda não haviam tido iniciação sexual.

A virgindade foi considerada importante por $66 \%$ masculino / 91\% feminino. Já com relação à prática sexual, 39\% masculino / 17\% feminino já consumaram 0 ato sexual edestes, $77 \%$ masculino / $84 \%$ feminino utilizavam o preservativo nas relações. A primeira experiência sexual ocorreu entre 14 anos ou menos para $91 \%$ masculino / $60 \%$ feminino, entre 15 e 16 anos para $7 \%$ masculino / 33\% feminino, entre 17 e 18 anos para $1 \%$ masculino / $7 \%$ feminino.

Quanto à orientação sexual 76\% masculino / $63 \%$ feminino denominaram-se heterossexuais, $21 \%$ masculino / $35 \%$ feminino declaravam-se bissexuais no relacionamento com o outro. $\mathrm{Nin}$ guém se declarou homossexual.

Com relação ao assunto homossexualidade, $41 \%$ masculino / $65 \%$ feminino entendiam ser uma escolha sexual como outra qualquer, $12 \%$ masculino / $8 \%$ feminino uma doença, $47 \%$ masculino / $26 \%$ feminino um comportamento errado e absurdo.

Para $70 \%$ masculino / 17\% feminino a primeira relação sexual foi com amigas(os), $28 \%$ masculino / 79\% feminino tiveram a primeira experiência com namoradas (os), apenas $1 \%$ masculino com prostituta ou garoto de programa.

A posição da família em relação à experiência sexual dos seus filhos foi representada por 30\% masculino / $46 \%$ feminino que relataram que os pais não desconfiavam; $24 \%$ masculino / 15\% feminino os pais sabiam, mas fingiam não saber e $17 \%$ masculino / $16 \%$ feminino os pais sabiam e conversavam sobre 0 assunto.

Quanto à pretensão ou utilização de um método contraceptivo, os dados revelaram que $78 \%$ masculino / 75\% feminino pretendiam utilizar ou já utilizavam o preservativo, $3 \%$ masculino / $16 \%$ feminino a pílula, $1 \%$ feminino o DIU. Os adolescentes que não utilizavam ou utilizariam um contraceptivo na relação sexual foi $18 \%$ masculino / 7\% feminino.

Com relação ao aborto, 10\% masculino / 8\% feminino fariam ou ajudariam alguém a fazer um aborto, enquanto que $87 \%$ masculino / $88 \%$ feminino condenaram a prática do mesmo. 


\section{Discussão}

0 interessepelo assunto sexualidadeésemelhante entreos sexos masculino efeminino, pois ambos os grupos buscavam informações sobre 0 assunto, ainda que as manifestações do comportamento sexual fossem diferentes entre eles.

Quanto ao conhecimento adquirido sobresexualidade, a metade dos dois grupos o considera suficiente, enquanto a outra metade insuficiente. Com relação às fontes de informação para compor este conhecimento, encontramos nos dois grupos os pais como primeiro recurso, posteriormente os amigos e professores, o que nos chamou a atenção, pois tal resultado contrasta com 0 de outros estudos. Pesquisa realizada junto a adolescentes da região sul da cidade deSão Paulo mostrou que $43 \%$ da população pesquisada costumavam conversar sobre assuntos relacionados à sexualidade com amigos( as) ${ }^{9}$.

Este achado é interessante, pois a orientação sexual é prioritariamente uma competência da família, peça chavena identidade de gênero eno desenvolvimento dos papeis sexuais dos filhos ${ }^{10}$.

A família e a escola têm papeis diferentes e complementares na orientação dos adolescentes, uma não substituiu a outra. A escola complementa o que éiniciado no lar, suprindo lacunas, combatendo preconceitos, desenvolvendo respeito pelo corpo e pelos sentimento $\mathrm{s}^{10}$. N este sentido, percebe-se a importância do professor na função natural de educador sexual no ambiente escolar, ea necessidade de renovação contínua dos seus próprios conhecimentos sobre sexualidade, para cumprimento eficaz de seu papel ${ }^{11}$. M uitas vezes os pais consideram delicado abordar questões de sexualidade com seus filhos adolescentes, justamente por não terem muito claro o que aconteceu com eles próprios, atribuindo essa responsabilidade à escola, e esta, por sua vez, apresenta dificuldade em cumprir tal tarefa ${ }^{12}$.

$\mathrm{N}$ a temática da sexualidade, as garotas mostraram-se mais informadas do que os rapazes $^{13,14}$, porém este conhecimento vai aumentando para os dois grupos com avanço da idade e da escolaridade ${ }^{13,15}$, confirmando mais uma vez a importância desta como condição para que 0 jovem tenha acesso aos meios e fontes de informação sobre 0 assunto.

Em relação à masturbação, houvemaior ocorrência entre os meninos, bem como na quantidade desta prática. Estes dados confirmam aspectos característicos da construção social da sexualidade masculina. A penas na prática da masturbação por mais de cinco vezes por semana encontramos uma maior porcentagem de meninas, o que nos leva a pensar num grupo que está explorando o corpo e a sexualidade, rompendo as barreiras do silêncio, admitindo a prática da masturbação.

Para aliviar a tensão sexual na adolescência, os jovens recorrem à masturbação, que é uma prática que produz a sensação de alívio sexual à tensão e tem uma função gratificante. M as jovens que chegam antes à plena maturação física e psíquica não se contentam mais com a masturbação e não conseguem mais sufocar o intenso desejo de se relacionar sexualmente, assim deparamo-nos com um problema delicado e complexo, momento em que a orientação sexual faz-se necessária ${ }^{16}$.

Em um estudo norte-americano sobre a sexualidade feminina, $82 \%$ respondeu que se masturbava. Nestesentido, $\mathrm{Hite}^{17}$ referequea masturbação feminina fornece uma informação quase que biologicamente pura, uma vez que é quase sempre praticada no isolamento e na maioria dos casos não é ensinado por ninguém, é uma das poucas formas de comportamento instintivo ao qual temos acesso. Não é a sexual idade feminina quetem um problema, éa sociedadequeéproblemática na sua definição desexo eno papel subordinado que esta definição confere às mulheres.

Uma pesquisa realizada com professores de escolas públicas de São Paulo corrobora com esta visão conservadora da sociedade, em quemasturbação foi citada por $9 \%$ deles, como um assunto que não deveria ser abordado na escola para não estimular a sua prática entre os alunos ${ }^{18}$.

Em relação ao namoro, a maioria dos adolescentes referiu não existir uma idade para iniciá-lo, indicando o período para se começar a faixa etária entre 13 e 16 anos, coincidindo com outro estudo ${ }^{19}$ que estabeleceu a idade de iniciação com 13 anos.

Ao contrário do "ficar", o namoro é um relacionamento mais sério, que supõe compromisso e fidelidade, e onde a intimidadefísica ganha espaço, no conhecimento de si e do outro, sendo seguida pela iniciação sexual do casal ${ }^{20}$.

Em relação à orientação do desejo sexual, a maior parte das garotas entendia como uma escolha como outra qualquer, enquanto que os rapazes expressaram maior preconceito em relação ao namoro com pessoas do mesmo sexo, confirmando quevivemosem uma sociedadeainda discriminatória quanto à orientação afetiva e sexual dos indivíduos ${ }^{21}$.

A escola poderia colaborar neste sentindo com professores preparados para polemizar, li- 
dar com valores, tabus e preconceitos ${ }^{22}$. M as, eles continuam sem subsídios adequados para trabalhar estas questões e acabam dando a elas enfoquetotalmente biológico com a função de preservar o educador frente aos al unos com relação aos seus próprios questionamentos, receios e ansiedades ${ }^{23}$.

A virgindade é considerada importante para quase a totalidade das meninas, resultado deuma educação norteada pela cultura patriarcal. Observamos uma grande porcentagem de meninos que consideram a virgindade um valor a ser preservado, mas supõe-se que estejam se referindo a virgindade das meninas com quem el es se relacionam e não a sua própria virgindade.

0 dado obtido nos remete à dinâmica das relações de gênero, que impõe às moças o recato em relação ao sexo, o que resulta no elevado valor atribuído à virgindade para elas ${ }^{24}$, tanto que as jovens conversam com os namorados sobre não serem mais virgens ao iniciar um namoro. Porém, em situação oposta está a construção social masculina, em que se espera que os meninostenham experiência sexual eapresentem vergonha de dizer que são virgen ${ }^{15}$.

Quanto ao intercurso sexual dos adolescentes, a consumação do ato sexual se deu em maior concentração entre os meninos. Quanto à idade para o início da atividade sexual, os dois grupos apontaram em maior porcentagem os 14 anos ou menos. Estes dados confirmam uma situação muito comum no contexto histórico em que os adolescentestêm iniciado sua vida sexual cada vez mais cedo ${ }^{20}$, o que colabora para a não utilização de proteção na primeira relação sexual devido a sua imaturidade etária, emocional e afetiva.

Diante deste fato, al guns autores consideram como fatores de proteção aos adolescentes a maior escolaridade ${ }^{15,24}$, melhores condições sociais ${ }^{24}$ e conviver com ambos os pais, condições que podem postergar a idade de iniciação sexual e facilitar o uso de proteção na primeira relação sexual.

De acordo com os resultados deste estudo, em suas relações sexuais, as meninas referem maior utilização de camisinha do que os meninos, o que demonstra um contexto de responsabilidade, determinado pelo desenvolvimento e amadurecimento mais rápido entre as meninas em comparação aos meninos. Este fato deve-se ao fato da aceleração do ritmo de crescimento que começa, em média, dois anos mais cedo nas garotas, algumas a partir dos 8, 9 anos. Algumas garotas, aos 13 anos, já terão corpo de adulto, enquanto outras nem iniciaram a puberdade ${ }^{25}$.
A assimetria de gênero se reflete na capacidade de negociação acerca da contracepção, especialmente no momento da iniciação sexual ${ }^{21}$. Sendo a camisinha de domínio masculino, compete ao homem a decisão de usá-la ou não, mas para os mesmos ela é vista como um obstáculo ao prazer sexual ${ }^{26}$. Nesta relação de poder, as adolescentes continuam sem capacidade para negociar 0 sexo seguro com seus parceiros, expondo-sea riscos dos quais elas têm pleno conhecimento.

É necessário trabalhar a questão de gênero na adolescência como uma estratégia de diminuir o desequilíbrio de poder entre os sexos, mudando normas de pares, criando habilidades de negociação e mudança de conduta ${ }^{15}$.

Em seu relacionamento sexual a maior parte dos dois grupos se colocou como heterossexual, mas, uma expressiva porcentagem destes declarou-se bissexual no relacionamento com o outro. Este dado deve se referir aos jogos sexuais característicos da adolescência enão propriamente às relações sexuais 0 padrão que tem se constituído é o de crianças se relacionando entre si, crianças se relacionando com os adolescentes, numa cadeia sexual que chega até a adultilida$\mathrm{de}^{27}$, no direito universal de usufruir plenamente do próprio corpo e dos prazeres que este pode oferecer ${ }^{28}$.

Quanto aos parceiros sexuais, a maior parte dos rapazes teve sua primeira relação sexual com amigas, enquanto que as garotas com os seus namorados. Estas raramente iniciaram-se sexualmente antes do namoro propriamente dito ${ }^{26}$, enquanto que nem todos os meninos o fizeram em um relacionamento de namoro ${ }^{19}$.

Para as garotas 0 amor mostra-se como a maior motivação para a iniciação sexual, podendo ou não ser marcada por insistência dos namorados e/ou para a manutenção do interesse do parceiro na relação ${ }^{20}$. Mas, para os rapazes, envolvendo ou não sentimentos amorosos, o primeiro ato sexual compreende uma forma de satisfação do instinto e da necessidade de dar vazão a atração física, além de servir como modo de expressão do processo de tornar-se homem e de consolidação da sua masculinidade ${ }^{19}$. Os resultados também mostram que uma pequena porcentagem de meninos iniciou sua vida sexual com prostitutas, o que corresponde ao fato de que os meninos têm com frequência sua iniciação sexual com mulheres mais velhas, muitas vezes, já experientes sexualmente ${ }^{19,29}$. H istoricamente, uma parcela dos homens no Brasil teve, como possíveis parceiras sexuais, prostitutas ou empregadas domésticas ${ }^{29}$. 
A questão da família em relação à vida sexual de seus filhos demonstrou um distanciamento entre ambos, pois a menor porcentagem dos dois grupos conversava com os pais sobre 0 assunto e tornava conhecida sua prática sexual. Dados conflitantes, quando comparados com os obtidos sobre a fonte de informação para obtenção de conhecimento sobre sexualidade, o que demonstra incoerência nas respostas.

O tempo disponível dos pais para se relacionarem com seus filhos está cada vez mais limitado. Diante deste fato, com relação à orientação sexual, transferem para a escola uma responsabilidadeque, ou não querem, ou encontram dificuldades em assumir ${ }^{21}$. Assim, a prática sexual dos filhos não é discutida na família, o gerenciamento da contracepção, à revelia dos pais, torna-se mais difícil, e no entanto, o fato destes estarem cientes e o recomendarem, não significa que haverá um acato ${ }^{30}$.

Para a prevenção da gravidez a maior parte dos rapazes e garotas já usou, ou pretende usar, o preservativo, confirmando outros estudos que apontam este método de prevenção de gravidez como o mais conhecido entre os adolescentes ${ }^{15}$. Porém, uma significativa porcentagem de rapazes e garotas, sendo maior no primeiro grupo, afirmou não usar nenhum contraceptivo na relação sexual, tornando-se um grupo derisco para a gravidez na adolescência. N este sentido, as razões para a não utilização dos contraceptivos entre os adolescentes estão relacionadas ao não planejamento da relação sexual, falta de confiança nos métodos, oni potência adolescentee a rejeição do parceiro por interferência em seu prazer sexual. Assim, a gestão da contracepção continua a ser encargo feminino, ainda bastante submetido à capacidade de autodeterminação e de negociação com o parceiro ${ }^{30}$.

É importante considerar que o uso do preservativo é o oposto da espontaneidade que se costuma atribuir ao sexo eà juventude. Assim, 0 estímulo deve incluir a dimensão do erotismo e da praticidade, não apenas o medo ${ }^{24}$. É preciso levar os adolescentes à reflexão e negociar com eles a utilização do seu conhecimento para a própria proteção $0^{18}$.

Como já foi observado, a adolescência é um período da vida em que colegas e pares passam a ganhar mais importância, eisso faz parte do processo de construção da autonomia dos jovens diante da família, na busca de suas singularidades. $\mathrm{N}$ ão discutir contracepção é permanecer cego diante do fato de queas relações sexuais dejovense adolescentes se modificaram, são legítimase cons- tituem um direito. No que concerne à reprodução, as mulheres continuam sen do culpabilizadas por engravidar; os homens, absolvidos ou esquecidos de sua participação no evento; e aos poderes públicoséreclamado simplesmenteo planejamento familiar sem considerar a etapa necessária da educação sexual que é um instrumento que poderia, de fato, fazer com quea contracepção ea proteção nas relações sexuais se integrassem de maneira regular na vida dos joven ${ }^{31}$.

Quanto ao aborto, a grande maioria dos adolescentes, de ambos os sexos, disseram que não 0 fariam nem ajudariam alguém a fazêlo. Estas afirmações têm como base influência da religião adotada pel os adolescentes deste estudo, as quais foram apresentadas na caracterização da população. Estes resultados se confrontam de certo modo com os dados do aborto no Brasil, pois ele tem sido considerado um problema de saúde pública por ser, na grande maioria das vezes, praticado clandestinamenteem locaise por profissionais despreparados para o procedimento.

Só vivenciando a situação équeo adolescente poderá decidir-se pela maternidade ou pelo aborto. Sendo que esta última decisão raramente é tomada de forma solitária pelos adolescentes, pois as famílias se posicionam oferecendo condições materiais e apoio para sua realizaçãa ${ }^{32}$, se os valores sociais, morais e religiosos assim permitirem.

Qualquer que seja a escolha do adolescente, dificilmente eleterá condições de viabilizá-la sem a ajuda da família. E qual quer que seja a decisão, aborto ou reprodução, pode ser incorporada ao processo de construção da identidade, quando vividas como alternativas escolhidas por eles e não como impostas por terceiros ${ }^{30}$.

\section{Conclusão}

A sexualidade passou a ser reconhecida como construção social, efeito dos padrões culturais, num período cuja face social não é um fenômeno homogêneo, o que nos leva a considerar que há diferentes adolescências moldadas por processos sociais distintos.

O estudo mostrou que não há diferenças significativas, em porcentagens, entre 0 grupo de rapazes e 0 de garotas, nas questões abordadas, exceto no que toca a homofobia, em que o preconceito masculino prevaleceu.

As relações afetivas e sexuais do grupo estudado foram estruturadas e atualizadas por um sistema designificados, dado pela cultura, e, por- 
tanto, determinadas entre outros aspectos, por padrões de gênero.

Esses padrões se expressam claramente na vivência da sexualidade, onde, do ponto de vista biológico, as relações de poder têm significados diferentes para homens e mulheres, assi $m$ como na compreensão de si mesmos, do outro e de suas relações.

A relação de poder neste estudo verifica-se no fato da garota ser a responsável pela contracepção, ainda que diante da negação masculina de usar preservativo, sem que ela tenha, na maioria das vezes, condições para negociação, seja na contracepção ou na prevenção das Doenças Sexualmente Transmissíveis.
Para equilibrar as relações de poder, especialmente no exercício seguro da sexualidade adolescente, faz-se necessária a construção do conhecimento destes quanto às suas responsabilidades individuais e sociais. Para tanto, as políticas públicas de saúde e de educação devem contribuir para discussões sobre a sexualidade, assumindo as relações de gênero, classe social eetnia, e também das outras concepções que o adolescente tem de si mesmo, e de sua sexualidade. N este sentido, é possível entender quea escola se mostra como bom espaço de socialização na construção e na execução de medidas de prevenção, voltadas à educação sexual de seus alunos, entre eles, os adolescentes.

\section{Colaboradores}

JRS Brêtas contribui para a concepção e planejamento do projeto, obtenção de dados, análise e interpretação; participou na elaboração do conteúdo do manuscrito. CVS Ohara contribui para a concepção e planejamento do projeto; participou na revisão do conteúdo. DP J ardim contribuiu com a elaboração do conteúdo do manuscrito. W Aguiar Junior, JR de Oliveira participaram da coleta de dados, tabulação, análise e interpretação dos dados. 
1. Brêtas JRS, Rua DV, Querino ID, Cintra CC, Ferreira D, Correa DS. Compreendendo o interesse de adolescentes do sexo masculino e feminino sobre corpo e sexualidade. Temas Sobre D esenvolvimento 2002; 11(64):20-29.

2. Aberastury $A$, Knobel $M$. Adolescência normal. Porto Alegre: Artes M édicas; 1981.

3. Brêtas JRS. A mudança corporal na adolescência: a grande metamorfose. Temas sobre Desenvolvimento 2004; 12(72):29-38.

4. Blos P. Adolescência: uma interpretação psicanalítica. São Paulo: Martins Fontes; 1988.

5. Gil AC. M étodos e Técnicas de Pesquisa Social. São Paulo: Atlas; 2006.

6. Triviños ANS. Introdução à Pesquisa em Ciências Sociais. São Paulo: Atlas; 1992.

7. Brasil. Ministério da Saúde/ Conselho Nacional de Saúde. Resolução n.19 de 10 de outubro de 1996: Diretrizes e normas regulamentadoras de pesquisas em seres humanos. M undo da Saúde 1996; 21(1): 52-61.

8. World Health Organization (WHO). Family and reproductive health, women's health and development program. Geneva: World Health Organization; 1997.

9. Rua DV, Brêtas JRS, Silva CV, Aquino NA. Estudo do comportamento sexual nos relacionamentos entre adolescentes de 14 a 18 anos de idade. Temas Sobre Desenvolvimento 2002; 11(63):14-21.

10. Fonseca H. Abordagem Sistêmica em Saúde dos Adolescentes e suas famílias. Rev Adolescência e Saúde da UERJ 2004; 1(3):6-11.

11. Egypto AC. O projeto de orientação sexual na escoIa. In: Egypto AC, organizador. Orientação sexual na escola: um projeto apaixonante. São Paulo: Editora Cortez; 2003. p. 13-31.

12. Brêtas JRS, Pereira SR. Projeto de Extensão Universitária: um espaço para formação profissional e promoção da saúde. Trabalho, educação e saúde 2007; 5(2):317-327.

13. Gomes WA, Costa COM, Sobrinho CLN, Santos CA ST, Bacelar EB. Nível de informação sobre adolescência, puberdade e sexualidade ente adolescentes. J Ped 2002; 78(4):301-308.

14. Altmann H. Orientação Sexual em uma Escola: recortes de corpos e de gênero. Cad. Pagu 2003, 21 281-315.

15. Martins LBM, Costa-Paiva LHS, O sis M JD. Fatores associados ao uso de preservativo masculino e ao conhecimento sobre DST/AIDS em adolescentes de escolas públicas e privadas do Município de São Paulo, Brasil. Cad Saúde Pública 2006; 22(2):315-323.

16. Reich W. Crianças do futuro. Curitiba: Centro Reichiano; 1998.

17. Hite S. O Relatório Hite: Um Profundo Estudo Sobre a Sexualidade Feminina. Rio de Janeiro: Editora Bertrand; 1992.

18. Jardim DP, Brêtas JRS. Orientação Sexual na escola: a concepção dos professores de Jandira-SP. Rev Bras Enferm 2006; 59(2):157-162.
19. Borges ALV, Schor N. Homens adolescentes e vida sexual: heterogeneidades nas motivações que cercam a iniciação sexual. Cad Saude Publica 2007; 23(1):225-234.

20. Castro GC, Abramovay M, Silva LB. Juventudes e Sexualidade. Brasília: UNESCO Brasil; 2004.

21. Aquino EML, Heilborn ML, Knauth D. Adolescência e reprodução no Brasil: a heterogeneidade dos perfis sociais. Cad Saude Publica 2003; 19(Supl. 2):377-388.

22. Suplicy M, Egypto AC, Vonk FVV, Barbirato MA, Silva M CP, Simonetti C, Vergueiro FV, Schwarzstein J. Guia de orientação sexual: diretrizes e metodologia. São Paulo: Casa do Psicólogo; 2004.

23. Tonatto S, Sapiro CM. Os novos parâmetros curriculares das escolas brasileiras e educação sexual: uma proposta de intervenção em ciências. Psicologia \& Sociedade 2002; 14(2):163-175.

24. Villela WV, Doreto DT. Sobre e experiência sexual dos jovens. Cad Saude Publica 2006; 22(11):24672472.

25. Marcondes E. Pediatria Básica. Rio de Janeiro: Sarvier; 1980.

26. Pantoja ALN. "Ser alguém na vida": uma análise sócio-antropológica da gravidez/maternidade na adolescência, em Belém da Pará, Brasil. Cad Saude Publica 2003; 19(Supl. 2):335-343.

27. Rios LF. Parcerias e práticas sexuais de jovens homossexuais no Rio de janeiro. Cad Saude Publica 2003; 19(Supl. 2):233-232.

28. Petchesky R. Direitos sexuais:um novo conceito na prática política internacional. In: Barbosa M R, Parker R, organizadores. Sexualidades pelo avesso: direitos, identidades e poder. São Paulo: Editora 34; 2003. p. 15-38.

29. Leal $A F$, Knauth $D R$. A relação sexual como uma técnica corporal: representações masculinas dos relacionamentos afetivo-sexuais. Cad Saude Publica 2006; 22(7):1375-1384.

30. Brandão ER, Heilborn ML. Sexualidade e gravidez na adolescência entre jovens de camadas médias do Rio de Janeiro, Brasil. Cad Saude Publica 2006; 22(7):1421-1430.

31. Heilborn ML, Aquino EML, Bozon M, Knauth DR, organizadores. 0 aprendizado da sexualidade: reprodução e trajetórias sociais de jovens brasileiros. Rio de Janeiro: Garamond/Editora Fiocruz; 2006.

32. Peres SO, Heilborn ML. Cogitação e prática do aborto entre jovens em contexto de interdição legal. Cad Saude Publica 2006; 22(7):1411-1420.

Artigo apresentado em 18/03/2008

Aprovado em 30/10/2008

Versão final apresentada em 27/02/2009 